\title{
Local Heat Generation and Material Flow in Friction Stir Welding of Mild Steel Assemblies
}

\author{
Daniel Micallef ${ }^{1}$, , Duncan Camilleri ${ }^{1}$, Athanasios Toumpis ${ }^{2}$, Alexander Galloway ${ }^{2}$, and \\ Larbi Arbaoui ${ }^{3}$ \\ ${ }^{1}$ Department of Mechanical Engineering, Faculty of Engineering, University of Malta, Msida (MSD \\ 2080), Malta \\ ${ }^{2}$ Department of Mechanical and Aerospace Engineering, University of Strathclyde, \\ Glasgow (G1 1XJ), U.K. \\ ${ }^{4}$ Cenaero ASBL, Bâtiment Eole, Rue des Frères Wright 29, B-6041 Gosselies, Belgium. \\ *corresponding author: daniel.micallef@um.edu.mt
}

\begin{abstract}
In friction stir welding (FSW), assemblies are joined by means of practising, shearing and stirring non-molten material. The heat generation is directly related to the viscous behaviour of plasticised material, through coupled Navier-Stokes thermo-fluid flow stress equations. A significant amount of research has been conducted on aluminium FSW but studies on mild steel assemblies are limited. The aim of this work is to understand the influence of the tool rotational and traverse speed on the resulting material stir zone shape and the heat power generated in FSW of mild steel assemblies. A numerical and experimental approach is adopted in this study. Material visco-plastic properties are primarily established experimentally and are then applied to a computational fluid dynamics (CFD) model through user defined material flow stress constitutive laws. The model was further validated through a series of thermocouple and macrograph measurements and later on used to fulfil the aims of this work. This study identifies that the total heat generated for different welding parameters follows a non-linear variation with radial and angular tool position. These results provide a platform for the accurate definition of heat flux inputs and thermal strains to global thermoelasto-plastic models, replacing more simplified linear specifications currently used in the literature.
\end{abstract}

Keywords: Friction Stir Welding; Mild steel; Visco-plasticity; CFD; Heat generation; Material flow

\section{Introduction}

Friction stir welding involves a highly multi-physics process, involving the integration between heat flow, visco-plastic fluid flow, metallurgical interaction and elasto-plastic response. A fully coupled numerical model is required to completely and accurately predict residual stresses and distortion. However, this is highly computationally intensive and no off the shelf software, is readily available and capable to handle such a fully coupled multiphysics solution to model often large assemblies. The dissociation between the thermo-fluid flow and thermo-elasto-plastic models is so high that in literature, friction stir numerical models either concentrate on the localized CFD models [1], or attempt to predict the residual stresses and distortion through globalized thermal and structural models, independently [2]. A comprehensive review of different friction stir welding numerical models developed by various researchers, is given by He et.al. [3] For example, a number of thermo-mechanical global models have been developed to simulate the process for aluminium [4], [5] as well as 
steels [6],[7],[8]. However, these models rely on defining the heat input either through experimental information such as in Khandakar et al. [9] or by means of an empirical model such as in the work by Riahi $\mathrm{H}$ et al.[10] through a linear heat flux and heat generation relationship of the form:

$$
\begin{gathered}
q^{\prime \prime}(r)=\frac{3 Q_{s} r}{2 \pi\left(R_{s}^{3}-R_{p}^{3}\right)} \\
Q_{s}=\frac{4 \pi^{2}}{3} \mu N p\left(R_{s}^{3}-R_{p}^{3}\right)
\end{gathered}
$$

where $r$ is the tool radial location, $\mu$ is the Coulomb friction coefficient, $N$ is the rotational speed in RPS, $p$ is the pressure, $R_{s}$ is the shoulder radius and $R_{p}$ is the pin radius. Equation (2) models the effect of sliding. Other models such as those proposed by Schmidt et al. [11] assume partial sliding or full sticking.

The accuracy of such a model is debatable since it does not include any complex heat and mass transfer considerations that are clearly predominant in the FSW process. The asymmetry of the heat flux input is also not included in this model and it is still unclear whether this is significantly important in terms of residual stresses and distortion.

A more computationally accurate model can be adopted where first, the heat and visco-plastic flow are solved together through a coupled Navier-Stokes thermo-fluid flow stress model [12]. This model provides an input to both the metallurgical prediction and elasto-plastic models, through prediction of thermal gradients, cooling rates, fluid flow and stir zone shapes. The developed thermal strains and predicted material properties are then fed to an elasto-plastic model to predict the residual stresses and distortion. This approach requires the modelling of the full thermal response during welding and subsequent cooling to ambient temperature, including the influence of clamping and other heat sinks residing at far field positions from the joint, i.e. the whole plate including boundary conditions are modelled within the heat-flow equation. Another, perhaps more computationally efficient approach is to confine the thermo-fluid models to localized models [13], simulating the interaction between the tool and work-piece only, and accurately identify the heat generated at the weld in terms of heat flux equations and volumetric heat generated within the stir zone. These are then applied as loads to a thermo-elasto-plastic model that establishes global thermal strains and ultimately residual stresses and distortion.

In order to account for the different material behaviour found in the stir zone, the global thermo-elasto-plastic modelling strategy adopted by Camilleri et al. [6], and in their reduced solution elasto-plastic models [14], both require the specification of the stir zone shape and dimensions. In their work, Camilleri et al. [6] specify the nugget size on the basis of experimental observations. The issue of how this zone geometry varies with the operating conditions of traverse and rotational speed is somewhat unclear. Another challenge in these models is how to specify heat loss to environment for example the heat sink arising from direct contact with the backing plate and machine bed. In the work by Khandakar et al. [9], the heat sink is specified empirically using experimental data as guidelines. 
The deficiencies described in the models identified above can be overcome by means of a local thermo-fluid model. Here, the softened material is assumed to behave as a laminar, nonNewtonian, visco-plastic material. The aim of a local model is therefore to investigate the heat generation during the process and the resulting thermal and flow fields. Such models are relatively well documented for aluminium, [15], [16], [17]. For steels the works found in the literature are less common with some exceptions such as by Nandan et al. [18] whose primary focus was on stainless steels. The temperature for steel FSW reaches much higher magnitudes than aluminium welding. For this reason, the importance of the heat sink from the machine bed cannot be overlooked and will also have an impact on the stir zone geometry. In this work, emphasis is placed on the influence of the welding speed and tool rotational speed on the stir zone geometry as well as the flows and stir zones resulting from these different welding parameters and traverse speeds.

\subsection{Hypothesis, objectives and highlights}

Different FSW parameters have distinct effects on the size and shape of the stir zone. The determining factor of this shape is how heat and material shearing is distributed across the tool-plate interface. Analysis of the heat power generation is therefore a precursor to the understanding of the shape and size of the stir zone. To answer this hypothesis, this study focuses on the aims and highlights identified below:

1. The development of a robust computational fluid dynamics model that takes into account the material visco-plastic flow stress properties through a user defined material constitutive law. Experimentally measured thermal gradients and macrographs are used to validate this model.

2. Investigate the material flow and mass transportation occurring in mild steel FSW, thereby identifying the stir zone shape for different welding parameters.

3. Identify the localised thermal gradients and maximum temperatures.

4. Analyse and predict the average shear stress and heat power generation at the toolplate interface for the various welding parameters through the numerical models. The predicted heat input is then compared to analytical solutions and their applicability and robustness is assessed.

\section{Numerical modelling techniques and test specimens}

A thermo fluid-flow computational fluid dynamics modelling technique was adopted to predict the material flow and thermal gradients developed in FSW of mild steel assemblies. To maintain confidence in the numerical models and to ensure that the appropriate heat loss to machine bed is applied, the thermal gradients developed due to friction stir welding at farfield positions, measured in an independent study by Camilleri et.al. [6], are used to validate the models. Macrographs for different welding parameters were also experimentally identified and used as a comparison with the numerical models.

Five different welding parameters indicated in Table 3 are investigated in this study. These welding parameters are based on FSW tests conducted on $2 \mathrm{~m} \times 0.4 \mathrm{~m}, 6 \mathrm{~mm}$ thick, DH36 mild steel plates. The tool geometry, used for the experiments and the CFD numerical models, is presented in Figure 1. 


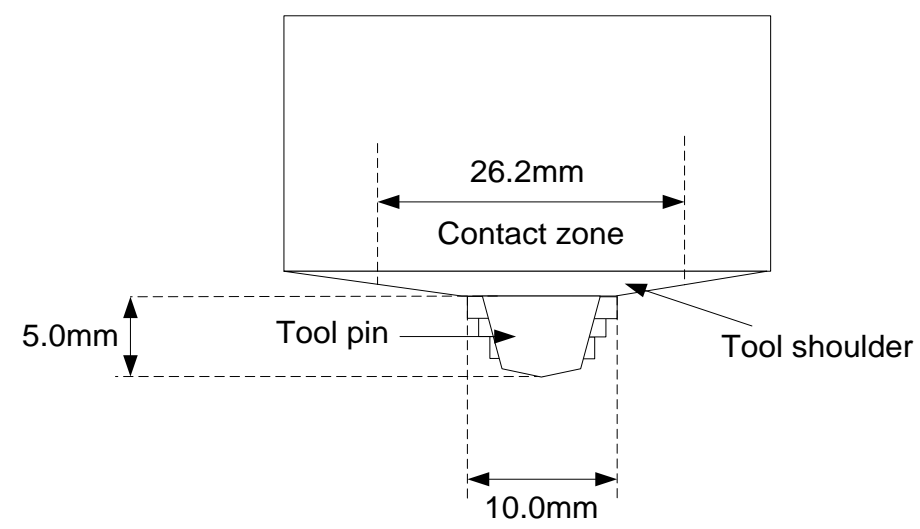

Figure 1 - Tool geometry used during experimental testing and for the CFD model.

In order to relate the different welding parameters in terms of heat input per unit length, the ratio between the rotational tool speed and the traverse speed is proposed and considered by the authors. This dimensionless parameter is defined below and herein referred to as the Traverse Heat Input Ratio (THIR):

$$
\phi=\frac{R \Omega}{V}
$$

where $R$ is the shoulder radius, $\Omega$ is the tool rotational speed and $V$ is the tool traverse speed.

The test specimens are segregated into slow, intermediate and fast traverse speeds. The corresponding THIR values are also shown ranging, from 101.3 to 164.6. Test specimens A and $\mathrm{C}$ are backed up by thermocouple measurements at far-field positions while macrographs for all the different specimens were available. For test specimens $\mathrm{A}$ and $\mathrm{C}$ the plunge force was also experimentally recorded, corresponding to $40 \mathrm{kN}$ and $55.4 \mathrm{kN}$ respectively.

Table 1 - Test specimens and welding parameters

\begin{tabular}{|l|l|c|c|c|c|c|c|}
\hline \multirow{2}{*}{$\begin{array}{l}\text { Test } \\
\text { specimen }\end{array}$} & Designation & $\begin{array}{c}\text { Rotational } \\
\text { speed } \\
(R P M)\end{array}$ & $\begin{array}{c}\text { Traverse } \\
\text { speed } \\
(\mathrm{mm} / \mathrm{min})\end{array}$ & $\begin{array}{c}\text { Plunge } \\
\text { force[kN] }\end{array}$ & $\begin{array}{c}\text { THIR } \\
\varnothing\end{array}$ & \multicolumn{2}{|c|}{ Experimental data } \\
\cline { 4 - 8 } & Slow & 200 & 100 & 40 & 164.6 & $\checkmark$ & $\checkmark$ \\
\hline$B$ & Intermediate & 400 & 250 & $\mathrm{n} / \mathrm{a}$ & 131.7 & $\mathbf{x}$ & $\checkmark$ \\
\hline$C$ & Intermediate & 400 & 300 & 55.4 & 109.8 & $\checkmark$ & $\checkmark$ \\
\hline$D$ & Intermediate & 400 & 325 & $\mathrm{n} / \mathrm{a}$ & 101.3 & $\mathbf{x}$ & $\checkmark$ \\
\hline$E$ & Fast & 700 & 500 & $\mathrm{n} / \mathrm{a}$ & 115.2 & $\mathbf{x}$ & $\checkmark$ \\
\hline
\end{tabular}

\subsection{Numerical thermo-fluid flow formulation}

An axisymmetric tool is assumed in this study and thus a fixed Eulerian reference frame is adopted such that the frame is attached to the tool moving at the predefined rotational and traverse speed. The coordinate system used is located at the tool centre. Steady state conditions are assumed throughout. 
The Navier-Stokes equations are solved in steady state formulation for a non-Newtonian fluid representing the quasi-static thermal and fluid flow after tool plunge, dwell time and static heat flow. The continuity, momentum and energy equations defining this steady state condition are given in equations (4),(5) and ((6).

$$
\begin{gathered}
\frac{\partial u}{\partial x}+\frac{\partial v}{\partial y}+\frac{\partial w}{\partial z}=0 \\
\rho \vec{v} \cdot \vec{\nabla} \vec{v}=-\vec{\nabla} p+\mu(T, \dot{\varepsilon}) \vec{\nabla}^{2} \vec{v}+\vec{F} \\
\rho c_{p}\left(\frac{\partial T u}{\partial x}+\frac{\partial T v}{\partial y}+\frac{\partial T w}{\partial z}\right)=\frac{\partial}{\partial x}\left(k \frac{\partial T}{\partial x}+u \tau\right)+\frac{\partial}{\partial y}\left(k \frac{\partial T}{\partial y}+v \tau\right)+\frac{\partial}{\partial z}\left(k \frac{\partial T}{\partial z}+w \tau\right)
\end{gathered}
$$

Where $u, v, w$ are the velocities in the $\mathrm{x}, \mathrm{y}$ and $\mathrm{z}$ directions, $\vec{v}$ is the velocity vector, $T$ is the temperature, $p$ is the pressure, $\rho$ is the density, $k$ is the thermal conductivity and $c_{p}$ is the specific heat capacity. The shear stress $\tau$ is related to the viscosity by the following equation

$$
\tau=\mu(T, \dot{\varepsilon}) \vec{\nabla} \vec{v}
$$

Where $\mu(T, \dot{\varepsilon})$ is the dynamic viscosity dependent on temperature and strain rate, $\dot{\varepsilon}$, described in section 2.1. Second order upwind discretization of momentum and energy is used.

\subsection{Thermophysical and flow stress material properties}

The success of the numerical models is highly dependent on the accurate definition of the thermo-mechanical material behaviour, in this case that of DH36 mild steel. Thermal properties, namely non-linear temperature dependent conductivity and specific heat capacity were identified in previous research and documented in a recently published book by Gray et.al. [19] dealing with computational modelling of DH36 mild steel fusion welding. These material properties are shown in Figure 2. 


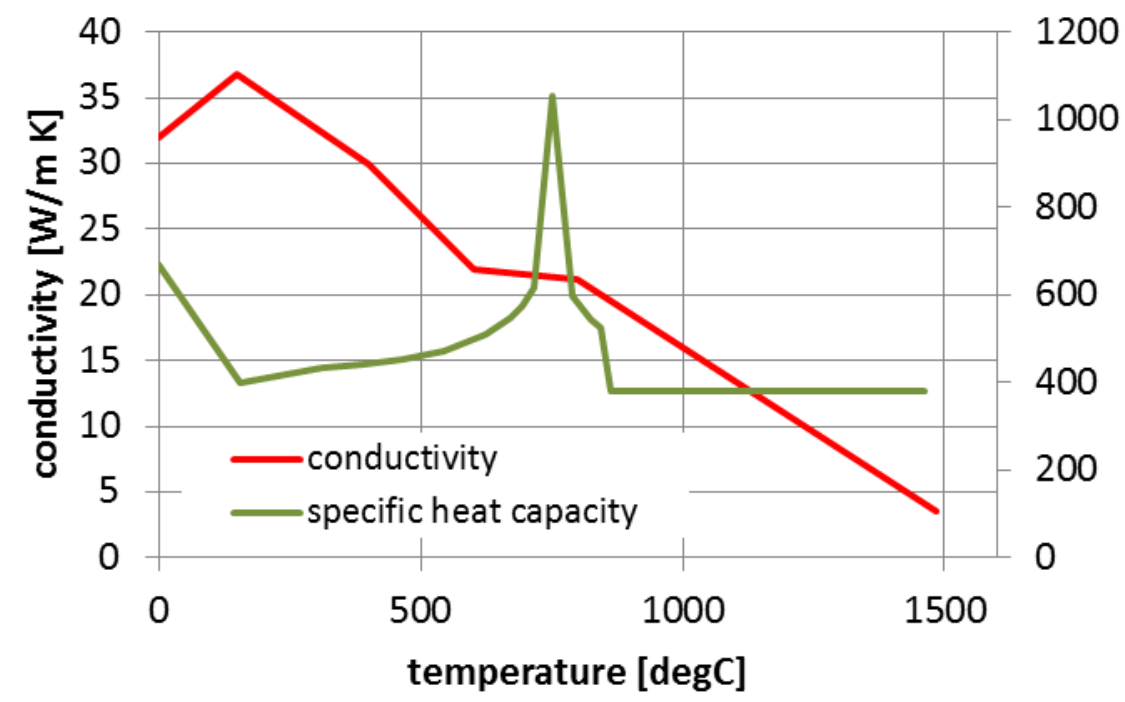

\section{Figure 2 - Temperature dependant thermal conductivity and specific heat capacity for DH36 mild steel}

In order to establish the variation of dynamic viscosity with temperature and strain rate, the flow stress-strain relationship at different strain rates and temperatures is required. This is developed in a separate experimental campaign and documented by Toumpis et al. [20]. For completeness, the material properties used in this study are shown in Figure 3. Nonetheless, a user-defined material constitutive flow stress law that follows the experimental data and relates viscosity to temperature and strain rate was developed and implemented in the model. The Norton-Hoff visco-plastic model [21] is assumed, such that the flow stress behaviour is defined by equation (8)

$$
\sigma=\sqrt{3} K(\sqrt{3} \dot{\varepsilon})^{m}
$$

where $m$ is known as the strain rate sensitivity, $K$ is the material consistency and $\dot{\varepsilon}$ is the strain rate. The variation of these parameters with temperature and strain rate can be assimilated to logarithmic relationship and fitted to the experimental data as described in equation (9)

$$
\log \sigma=A \log (\sqrt{3} \dot{\varepsilon})+B
$$

where the parameters A and B reflect the experimental flow stresses data. The parameters $\mathrm{m}$ and $\mathrm{K}$ are thus given in equation (10) and (11)

$$
\begin{gathered}
K=\frac{B}{\sqrt{3}} \\
m=A
\end{gathered}
$$

From the flow stress, the temperature and strain rate dependent viscosity are identified through the relationship given in equation (12) 


$$
\mu(T, \dot{\varepsilon})=\frac{\sigma}{3 \dot{\varepsilon}}
$$

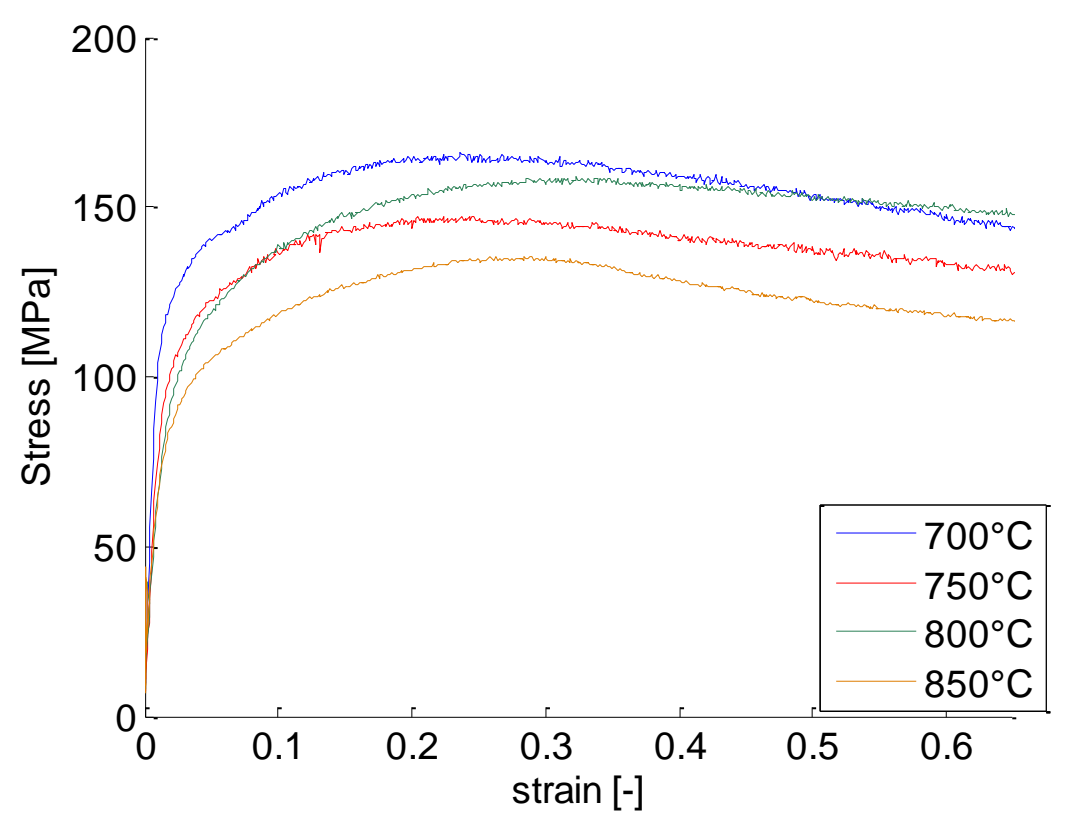

Figure 3 - Flow stress variation with strain for a strain rate of $10^{-2} / \mathrm{s}$ at different temperatures.

\subsection{Geometry and Mesh}

The work-piece is modelled as a rectangular geometry $0.2 \mathrm{~m}$ wide $\mathrm{x} 0.25 \mathrm{~m}$ long and $6 \mathrm{~mm}$ thick with the tool centre lying at the mid-width position but offset by $0.025 \mathrm{~m}$ from midlength position. A sketch of the tool geometry with the major dimensions assumed in this study is shown in Figure 4. This reflects realistic tool dimensions as documented by Toumpis et al. [22]. The contact zone between the tool shoulder and the plate material is assumed to be $26.2 \mathrm{~mm}$ in diameter. This value is a function of tool penetration depth in the work-piece that is generally a pre-set parameter specified during welding. The contact area identified in this study is based on nominal experimental observations. In reality, variations in work-piece thickness and machine tolerances are possible but in this study they are considered to be negligible. 


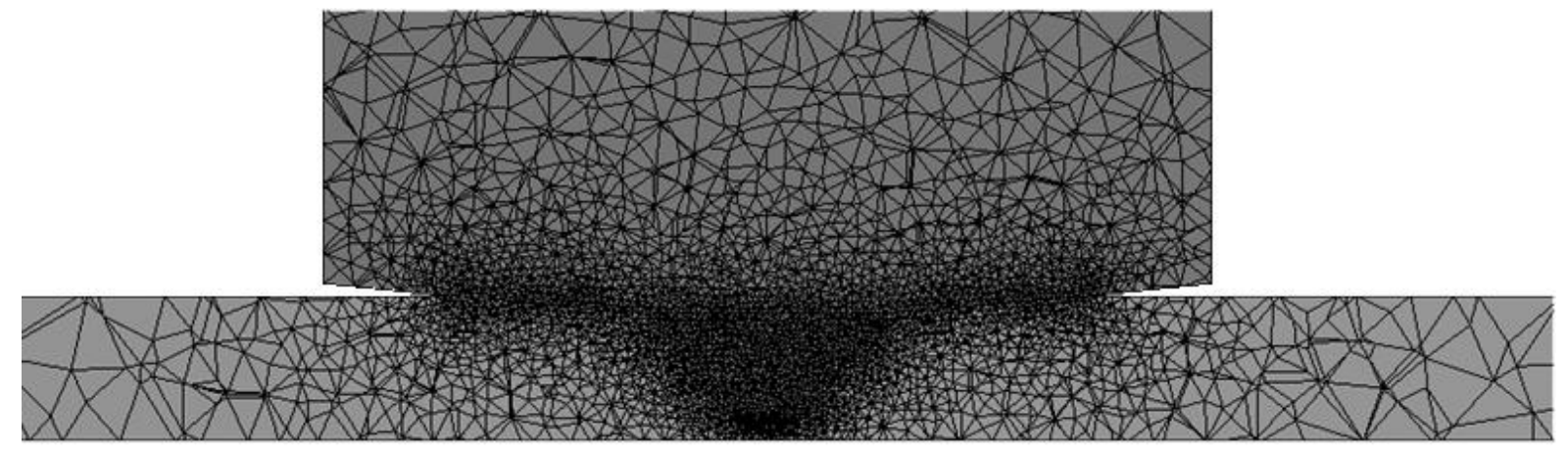

Figure 4 - Mesh used for the FSW local model

The mesh consisting of 614 thousand tetrahedral elements and adopted in this study is shown in Figure 4 and Figure 5. The coordinate system, tool rotation and direction of fluid velocity specified as inlet boundary condition are also depicted in Figure 5.

\subsection{Boundary conditions and inputs}

Figure 5 shows a schematic view of the boundary conditions assumed in this study. A wall boundary condition is applied to the top, bottom and side surfaces. These walls assume no relative motion with respect to the fluid (work-piece) flow, i.e. move with a speed equivalent to the traverse speed. A pressure outlet condition is set at the outlet while a velocity inlet is used at the inlet with inlet temperature taken as the ambient temperature. The tool-work-piece interface is taken as a wall boundary condition rotating at a defined tool angular velocity (RPM). The axisymmetric geometric tool assumption makes such formulation possible. For non-axisymmetric tools, a transient solution would have to be adopted where the fluid domain rotates instead of the tool wall. Heat is assumed to be entirely generated by plastic deformation and shearing of the material. In this case, the work-piece material in direct contact with the tool is considered to be fully sticking, i.e. no sliding and following the same angular velocity of the tool. It is assumed that the net forces arising from shearing only model or the combination of plastic deformation and friction are similar, thereby leading to the same equivalent total heat generation. A coupled thermal boundary condition is used at the toolwork-piece interface meaning that the heat transfer coefficient is calculated as part of the solution and heat is allowed to flow into the tool which effectively acts as a heat sink. 


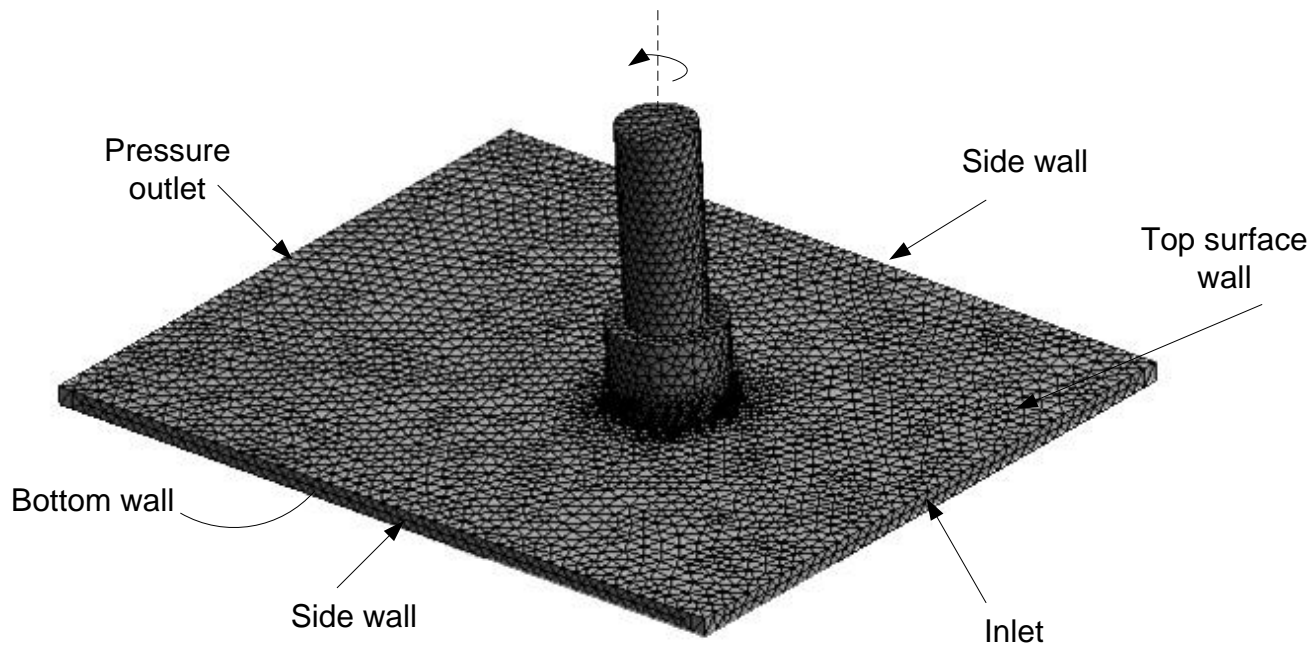

Figure 5 - Boundary conditions used in the model

The thermal condition for the side wall is taken as a convection boundary condition with a convection heat transfer coefficient of $100 \mathrm{~W} / \mathrm{m}^{2} \mathrm{~K}$. This mimics the heat flow by conduction to the adjacent plate material and takes into account the heat sink resulting from the side clamps. At the top surface, heat loss due to convection and radiation are applied through a convective boundary condition following natural convection for a flat plate (equation (13)) together with the equivalent heat transfer coefficient due to radiation as given by equation (14), leading to a total convection film coefficient given in equation (15).

$$
h_{\text {conv }}=0.54 \frac{k_{a}}{L}\left[\frac{g \beta\left(T_{s}-T_{\infty}\right) L^{3}}{v \alpha}\right]^{\frac{1}{4}}
$$

where properties are evaluated at a mean film temperature of $350 \mathrm{~K}$ (the mean between an assumed average surface temperature of $406 \mathrm{~K}$ and the ambient temperature taken as $294 \mathrm{~K}$ ), $k_{a}$ is the air conductivity, $\beta$ is the expansivity of air, $\nu$ is the kinematic viscosity, $\alpha$ is the diffusivity, $T_{s}$ is the surface temperature, $T_{\infty}$ is the ambient temperature $(294 \mathrm{~K}), L$ is the plate length.

The radiation coefficient is calculated as:

$$
h_{\text {rad }}=\varepsilon \sigma\left(T_{s}+T_{\infty}\right)\left(T_{s}^{2}+T_{\infty}^{2}\right)
$$

where $\varepsilon$ is the emissivity assumed as 0.8 for an oxidized steel surface, $\sigma$ is the Stefan Boltzmann's constant.

The total heat transfer coefficient is hence

$$
h_{\text {top }}=h_{\text {conv }}+h_{\text {rad }}
$$

Again, a convective boundary condition was applied to the bottom surface. In this case however, the heat loss and convection film coefficients were assigned at specific regions to 
simulate heat loss to the machine bed. In particular, it is assumed that heat is transferred (lost) from the work-piece to the machine bed at regions where good contact between the workpiece and the machine bed exists. The nature of FSW process subjects material directly beneath the tool to a normal, relatively high vertical plunge force thereby reducing any thermal gaps between work-piece and machine bed to a minimum. The tool plunge force is distributed over regions beyond the shoulder dimension and thus contact is also possible at these positions. Nonetheless, the force experienced is significantly less and reduces to zero within a relatively small region. No experimental observations were performed to measure such contact region. However, thermocouple measurements can be used to calibrate the heat loss (contact region) to the machine bed. In this study it is assumed that the heat sink model uses a region of good contact at the tool (high heat transfer coefficient) and a gradually reducing heat transfer coefficient behind the tool. Ahead of the tool, the material is still at ambient temperature (at least at work-piece - machine interface) and thus the definition of heat loss is not required. The values of the heat transfer coefficients are determined by crosscomparison with the resulting temperatures obtained experimentally. The procedure used for the calibration of this quantity is summarized hereunder:

1. A constant heat transfer coefficient is chosen for the region below the tool (hashed region in Figure 6).

2. An exponential function of the form $A e^{B x}$, where $\mathrm{A}$ and $\mathrm{B}$ are fitting parameters and $\mathrm{x}$ is the longitudinal coordinate, is assumed for the shaded region of Figure 6.

3. Initial values of the heat transfer coefficient under the tool and values for A and B are chosen.

4. A simulation is performed and the resulting temperatures compared with the experimental results

5. Steps 3 and 4 are repeated until an agreement in temperature between the numerical and experimental results is attained.

After using the above procedure, the resulting magnitudes for the heat transfer coefficients are given in Table 2. The heat transfer coefficients used for test specimen $\mathrm{A}$ and $\mathrm{C}$ were attained after cross-validation with thermocouple results. The reason why the resulting values are substantially different is due to the temperature dependency which strongly depends on the welding parameters. It is also assumed that the region up to $13.1 \mathrm{~mm}$, the region under the tool, assumes perfect thermal contact with the bed and reduces to practically zero in a region of around $70 \mathrm{~mm}$.

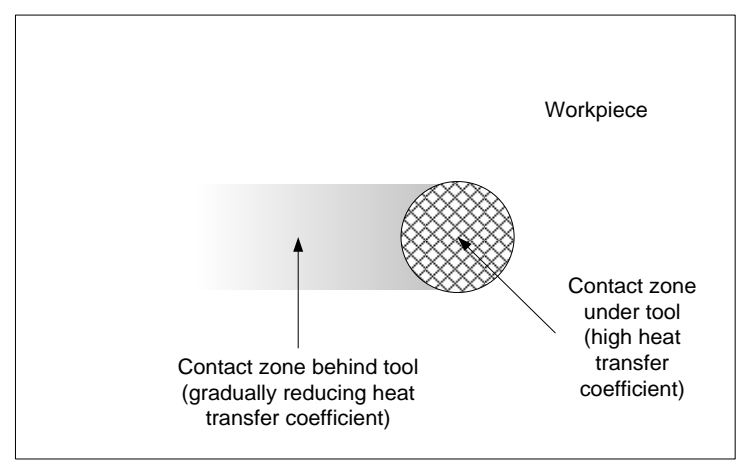

Figure 6 - Heat sink model assigned at the work-piece machine bed interface. 
Table 2 - Heat transfer coefficients defined behind tool position

\begin{tabular}{|c|r|r|}
\hline $\begin{array}{c}\text { Position } \\
\text { behind tool } \\
\text { (mm) }\end{array}$ & $\begin{array}{c}\text { h (weld C) } \\
\mathbf{W} / \mathbf{m}^{\mathbf{2}} \mathbf{K}\end{array}$ & $\begin{array}{c}\mathbf{h} \text { (weld A) } \\
\mathbf{W} / \mathbf{m}^{\mathbf{2}} \mathbf{K}\end{array}$ \\
\hline 0 & 2820.3 & 1196.5 \\
\hline 8 & 2820.3 & 1196.5 \\
\hline 12 & 2820.3 & 1196.5 \\
\hline 22 & 203.7 & 42.4 \\
\hline 30 & 115.0 & 33.2 \\
\hline 34 & 86.4 & 29.4 \\
\hline 42 & 48.7 & 23.0 \\
\hline 50 & 27.5 & 18.1 \\
\hline 58 & 15.5 & 14.2 \\
\hline 66 & 8.8 & 11.1 \\
\hline
\end{tabular}

\subsection{Heat generation}

The heat generated in the work piece is the result of the shear stress defined in eqn. (7). As the material is plastically deformed, the viscosity (which as stated in eqn. (12) is a function of strain rate and temperature) causes shear stresses to be developed, which lead to heat generation within the material volume. This heat generation is not explicitly input as a heat source term. Rather, it is part of the solution of the previously mentioned Navier-Stokes equations. The frictional heat input due to the tool-work-piece interface is assumed to be negligible in this study.

\section{Validation and model calibration}

The numerical model was validated with the surface temperature results attained from the experiment test welds $\mathrm{A}$ and $\mathrm{C}$. The other test specimens were corroborated with macrographs. The peak temperatures reached at far-field positions are highly dependent on the employed heat sink heat transfer coefficients. Figure 7 shows a comparison between the experimental and numerical predicted peak temperatures for test specimens A and C. Also included are results from numerical simulations using a constant heat sink heat transfer coefficient of $150 \mathrm{~W} / \mathrm{m}^{2} \mathrm{~K}$ in order to justify and emphasize the need of tuning the heat sink appropriately. Both the advancing and the retreating side are shown, but no thermocouple measurements were taken on the advancing side for the case of specimen $\mathrm{C}$. The temperature asymmetry can be clearly seen from the numerical results. The peak temperatures of the experimental and numerical results are in good agreement. As an example, at $27 \mathrm{~mm}$ away from the weldline on the advancing side, the temperatures for specimen $\mathrm{A}$ are $279^{\circ} \mathrm{C}$ and $267^{\circ} \mathrm{C}$ respectively. It is worth noting that the convection film coefficient assumed for the slower weld specimen $\mathrm{A}$ is evidently less and confined to a smaller region when compared to specimen C. A closer inspection of the welding parameters used during testing also revealed that the vertical plunge force was less for test specimen A. At a glance, it is therefore reasonable to conclude that less heat is absorbed by the machine bed for test specimen $\mathrm{A}$. However, it is important to point that a result of the formulation of this convective boundary condition, the amount of energy (heat) absorbed by the machine bed is also a function of the 
bottom surface temperature. Higher surface temperatures (as expected in slower welding traverse speeds) will inevitably, realistically and numerically result in more surface heat flux and thereby greater heat extraction. When a constant heat transfer coefficient is assumed, the results differ substantially from the experiments thus further justifying the use of the heat transfer coefficients mentioned in Table 2.

Since no thermocouple data was available for specimens B, D and E, the tuned heat transfer coefficients for A and C were used. Beyond $250 \mathrm{~mm} / \mathrm{min}$ (specimen $\mathrm{C}, \mathrm{D}$ and $\mathrm{E}$ ), the heat sink heat transfer coefficients for specimen $\mathrm{C}$ were used. For traverse speeds below $250 \mathrm{~mm} / \mathrm{min}$ (specimens A and B), the same heat transfer coefficients as for specimen A were used. This cut-off speed is arbitrary and further research is required to reduce the reliance on such assumptions.

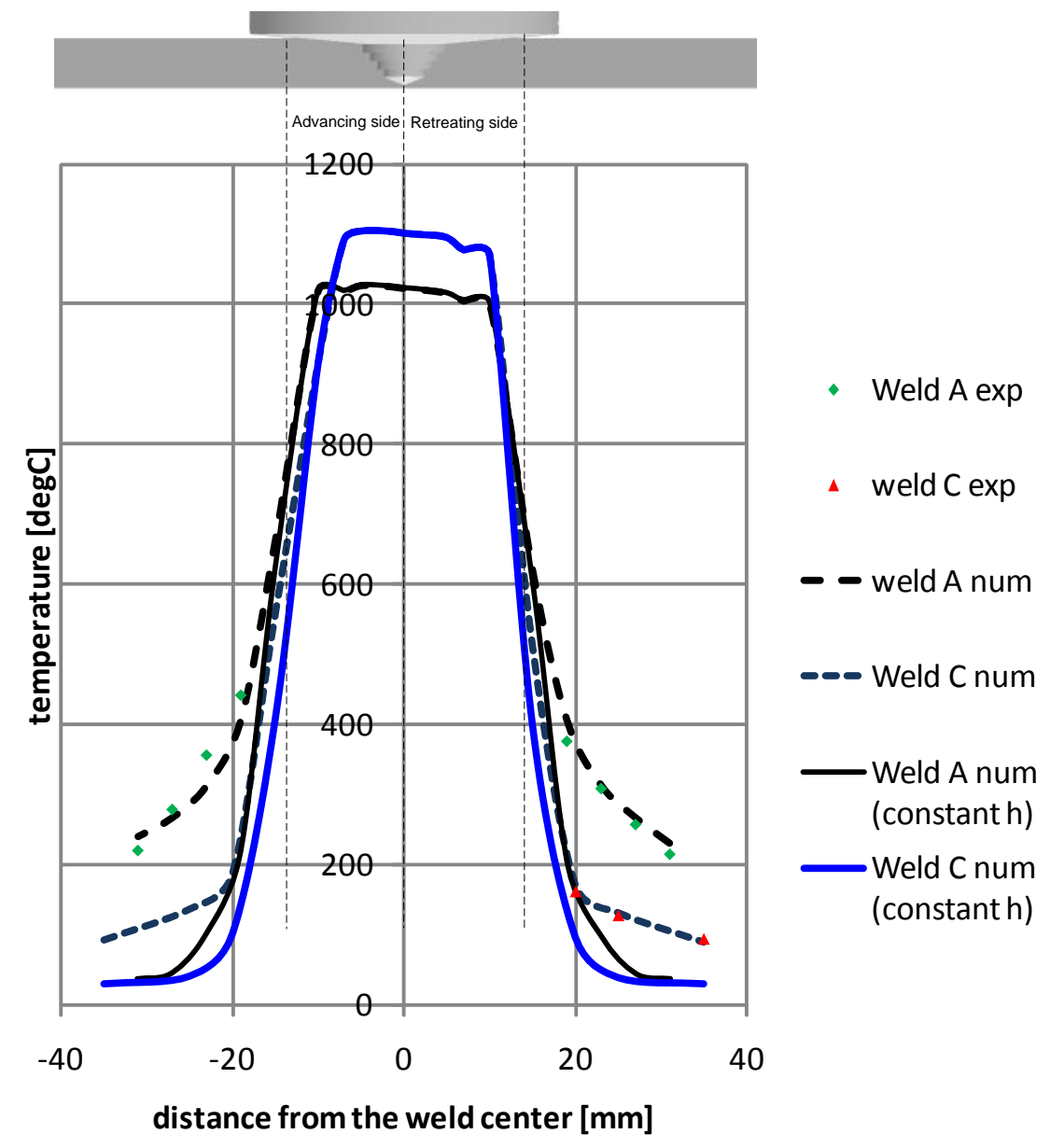

Figure 7 - Comparison of experimentally measured and numerically predicted maximum temperatures

\section{Results and discussion}

\subsection{Streamlines}

The streamlines, as seen from the tool under-side and for different test specimens, are depicted in Figure 8. The pin and the shoulder are outlined in the figure for reference purposes. The rotation of the tool from this view is clockwise while the flow is from right to left. For the low speed test specimen A, the flow streamlines tend to segregate towards the 
tool shoulder region. For test specimen B at the intermediate speed, the streamlines tend to envelope the pin better and become more evenly distributed along the entire tool radius. The streamlines start to cross each other. At higher traverse speeds for specimens C-E, further crossing of the streamlines can be observed. This shows that mixing is enhanced on increasing traverse speeds. This highlights the relation between traverse speed and stir zone mixing.

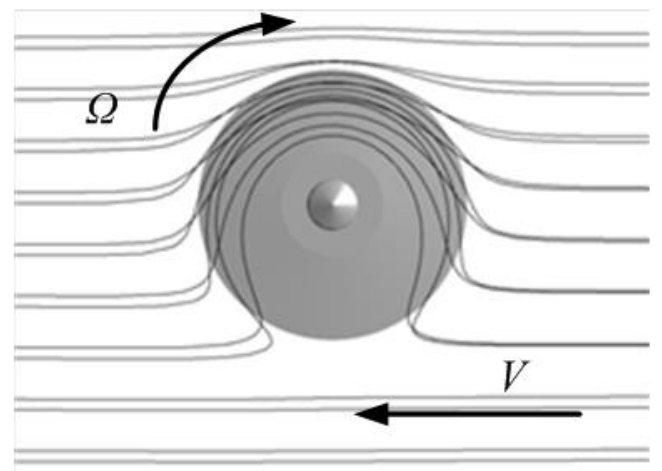

(a) Weld A

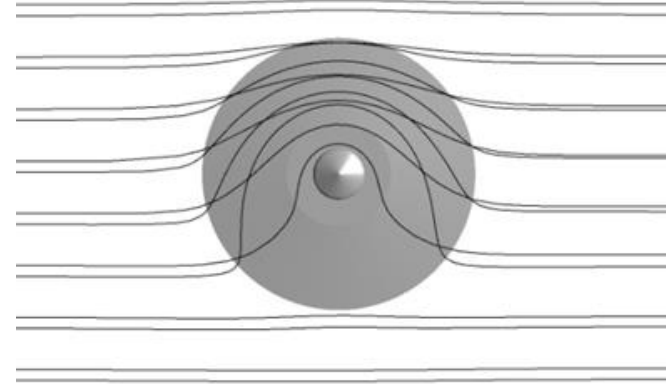

(c) Weld C

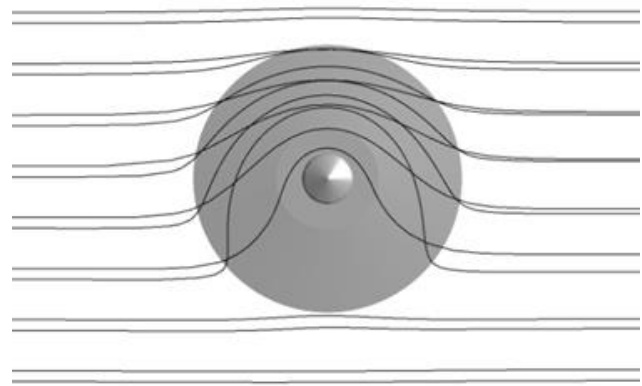

(b) Weld B

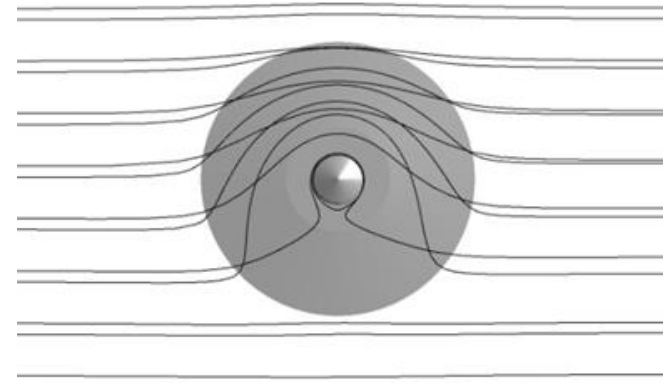

(d) Weld D

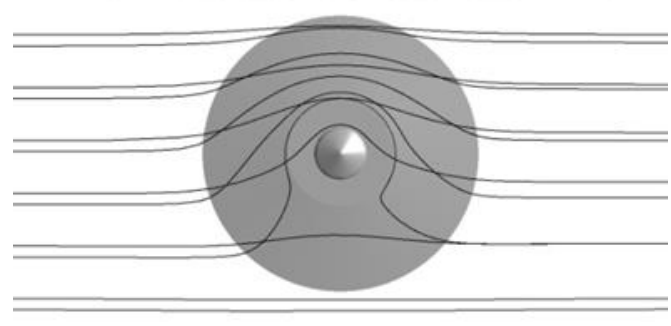

(e) Weld E

Figure 8 - Streamlines for different welding conditions. The rotation of the tool is clockwise and the flow is from right to left.

\subsection{Temperature field in the stir zone flow}

Figure 9 shows the temperature field resulting from different test specimens. For the slow traverse speed of weld sample A, a low maximum temperature but a larger heat affected zone can be observed. Weld sample E exhibits the highest peak temperature and is a result of the higher tool rotational speed associated with this specimen. Weld B shows a wider contour of temperature above the ambient temperature compared to the high speed cases. The intermediate and high speed cases of welds $\mathrm{C}$ to $\mathrm{E}$ have a more contained heat affected zone and demonstrate a similar heat affected zone both due to their higher traverse speeds as well 
as due to the higher heat sink. The asymmetry of the temperature field between the advancing and retreating sides can also be observed particularly in the case of weld $\mathrm{E}$.

Figure 10 reveals a detailed view of the temperature profile on the tool surface. The colour bar limits are chosen in such a way to clearly show the variation of the temperature along the surface. The maximum temperatures on the tool occur on the advancing side and towards the rear of the shoulder surface. On the other hand, the minimum temperatures occur in the pin region and at the front of the tool. The reason for this is that at the front of the tool surface, the material has the lowest viscosity and will experience a lower plastic deformation compared to the rear of the tool where the material has been transported due to the tool rotation.

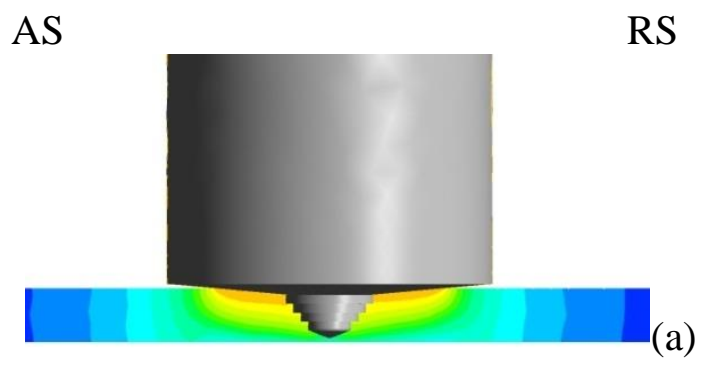

Weld A AS

(c) Weld C

AS

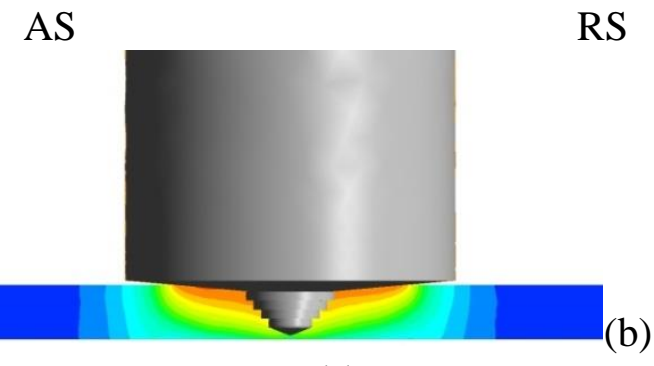

Weld B

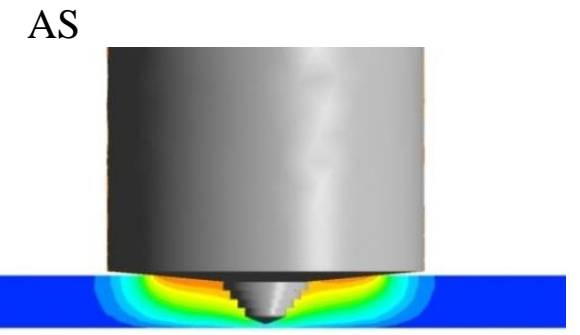

(d) Weld D

RS

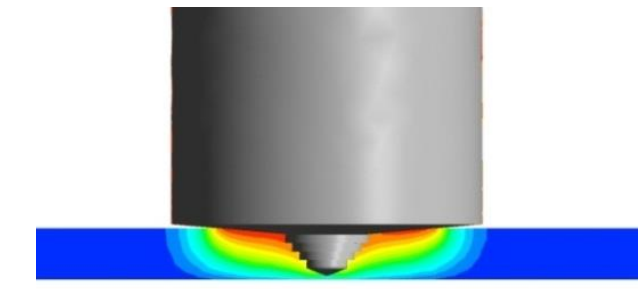

(e) Weld E

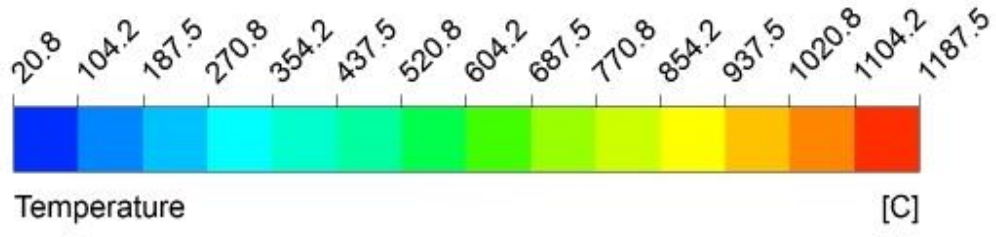

Figure 9-Temperature contours for different welding parameters. The tool moves in the out of plane direction and rotates anti-clockwise. 


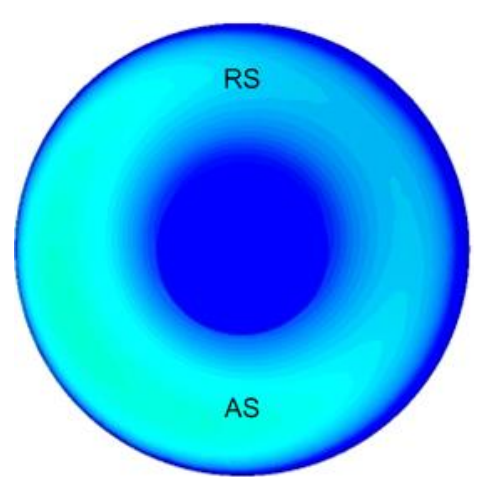

(a) Weld A

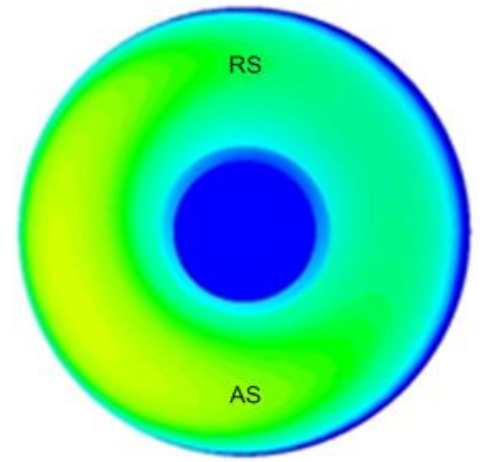

(c) Weld C

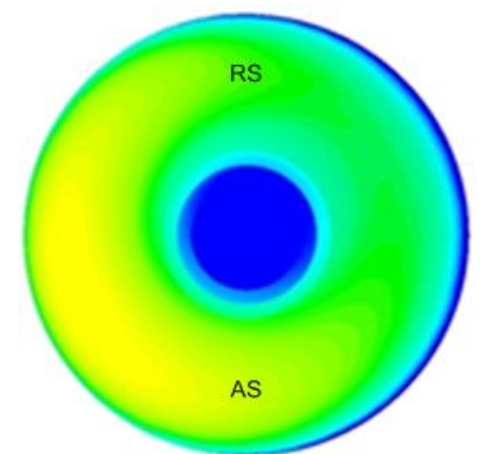

(b) Weld B

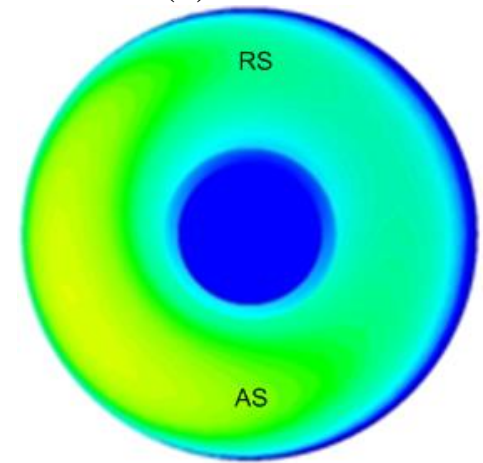

(d)Weld D
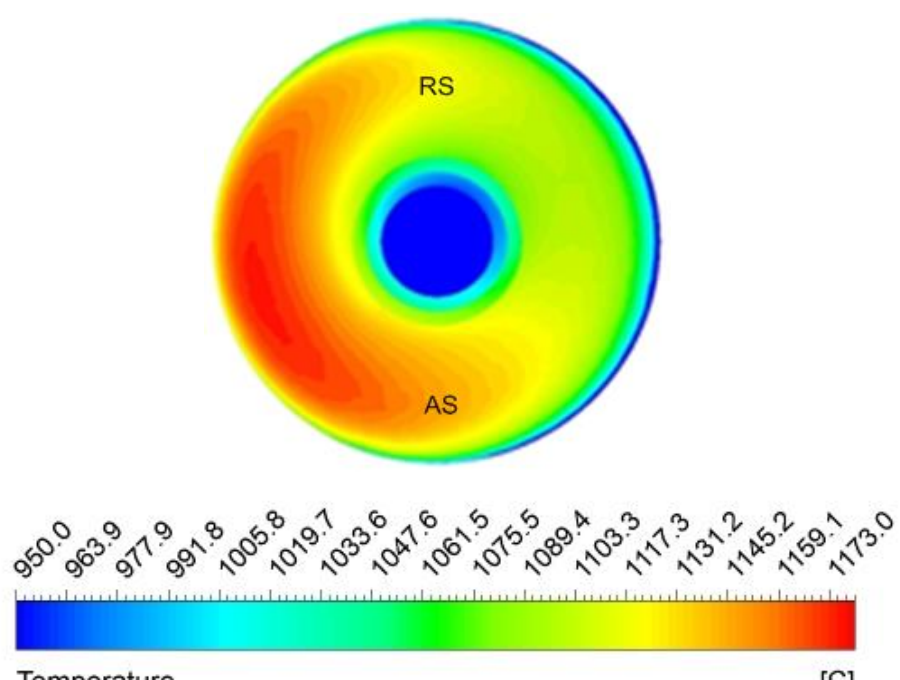

(e) Weld E

Figure 10 - Temperature detail on the surface of the tool.

\subsection{Stir zone geometry for different weld parameters}

The stir zone geometry is compared between the experimental macrographs and the numerical results. In order to define the stir zone from the CFD simulations, the relative velocity magnitude is considered. If the relative velocity is defined by $V_{r e l}$ and the stir velocity is defined by $V_{\text {stir }}$ then $V_{\text {rel }}=V+V_{\text {stir }}$. The stir zone can thus be defined as the region where $V_{\text {stir }}>0$ or $V_{\text {rel }}-V>0$. An iso-surface of velocity $V_{\text {stir }}=1 e-5 \mathrm{~m} / \mathrm{s}$ is considered in this study to be representative of the transition between stir and no stir. If a smaller value is chosen, the number would fall within the convergence tolerance of the simulation. 
The comparisons for weld A, C and E are shown in Figure 11. Experimental macrographs and CFD results appear alternatingly. For the CFD results, the shaded transparent region illustrates the iso-surface which encompasses a region of significant material stirring $V_{\text {stir }}>$ $1 \mathrm{e}-5 \mathrm{~m} / \mathrm{s}$ while the contours represent temperatures. In addition, the maximum temperature $T_{0}$ attained in the stir zone is also given. For weld $\mathrm{A}$, the stir zone geometry is quite symmetrical owing to the high THIR. In addition, the ' $V$-shaped' region appears to be quite broad and extends well below the top surface. The pin enables stirring of the material and allows full penetration to occur. The weld root is predicted very well and the entire region has a good level of agreement with the experimental macrograph. In all cases, the diameter of the stir zone is slightly overestimated. The reason for this is that the tool plunge depth varies along the weld-line due to the changing plunge force as a result of uncontrolled factors such as differing material thickness. The diameter of the stir zone is very sensitive to the plunge depth and hence the reason for the discrepancies between the observed top surface diameter from experiment and simulation. This effect is also supported by literature in [23]. For the high speed weld E, a certain level of asymmetry can be observed between the advancing and the retreating sides. The stirred material extends less over the thickness meaning a higher temperature gradient in the thickness direction. The iso-surface of velocity shows a clear asymmetry and good agreement with the one observed from the macrograph. The weld root has a size of $3 \mathrm{~mm}$ from the macrograph and a size of $2 \mathrm{~mm}$ from the CFD results. These dimensions are found by measuring the size of the stir zone at the bottom surface of the plate. 


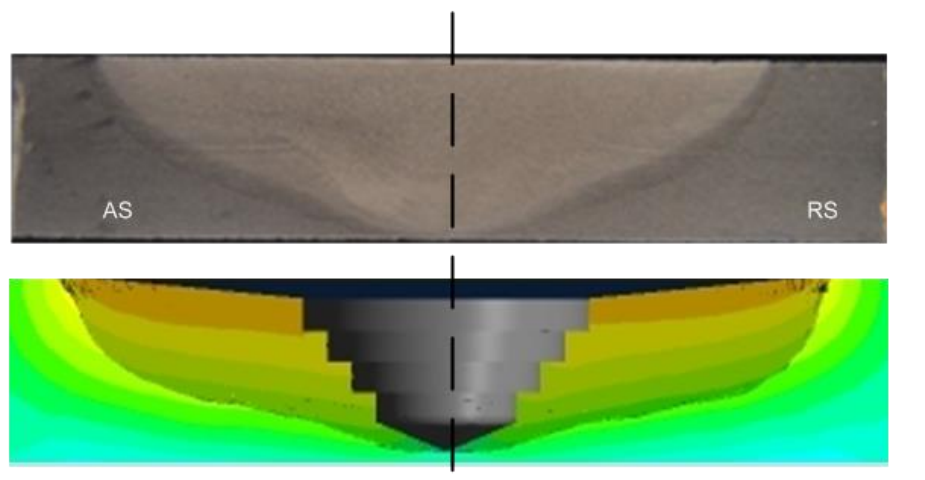

Experimental

(a) Weld A

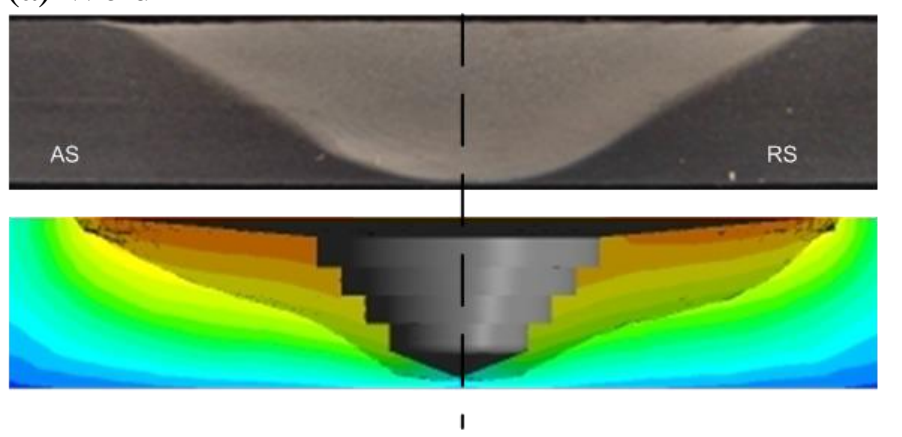

Experimental

Numerical

$T_{0}=1026^{\circ} \mathrm{C}$

Numerical

$T_{0}=1108^{\circ} \mathrm{C}$

(b) Weld C

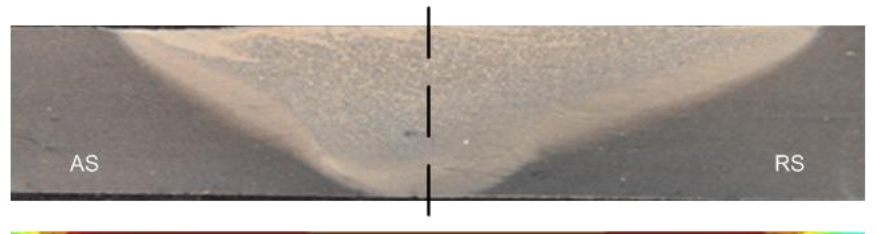

Experimental

Numerical

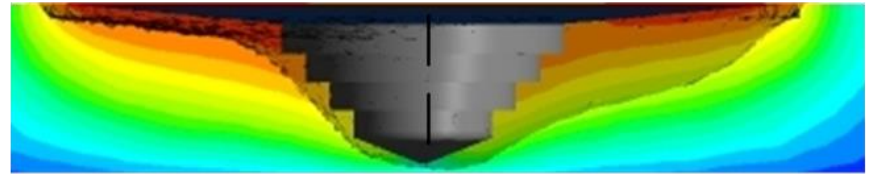

$T_{0}=1160^{\circ} \mathrm{C}$

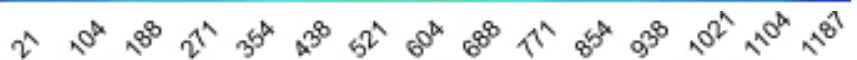

1

Temperature

[C]

(c) Weld E

Figure 11 - Comparison of the stir zone geometry between the experimental macrographs and numerical predicted stirring (shaded area). The temperature contours are also superimposed.

\subsection{Total power input}

The heat power input from the tool is established using the following equation:

$$
Q_{\text {total,CFD }}=\Omega \iint_{\text {Area }} \tau r d A
$$

where $\tau$ is the contact shear stress in the rotational direction and $d A$ is the tool surface elemental area.

The results from the CFD model are compared with a simplified pure sticking model as found from Schmidt et al. [11] 


$$
Q_{\text {total,sticking }}=\frac{2 \pi}{3} \tau \Omega\left(\left(R_{s}^{3}-R_{p}^{3}\right)(1+\tan \alpha)+R_{p}^{3}+3 R_{p}^{2} H_{p}\right)
$$

where $\tau$ is the contact shear stress, $\alpha$ is the tool shoulder angle (in this case $-5.2^{\circ}$ ) and $H_{p}$ is the pin height. For pure sticking, the von Mises shear stress may be applied such that the contact shear stress can be written in terms of the material yield strength $\sigma_{\text {yield }}$ as follows:

$$
\tau=\frac{\sigma_{\text {yield }}}{\sqrt{3}}
$$

The material yield strength is strongly dependent on temperature and hence the determination of the total heat input is somewhat empirical since it is difficult to establish a single reference tool surface temperature. In order to compare between the CFD results and the Schmidt model, the average contact shear stress is found from the CFD results on the tool surface (as a result of eqn. 7) and the result inputted into equation (17). A summary of the calculated average shear stress for each THIR is shown in Table 3.

Table 3 - Average shear stress calculated from the CFD for the different advance ratio cases.

\begin{tabular}{|l|l|}
\hline \multicolumn{1}{|c|}{ THIR value } & $\begin{array}{c}\text { Average shear stress on } \\
\text { tool surface [MPa] }\end{array}$ \\
\hline 164.6 & 51.9 \\
\hline 131.7 & 36.7 \\
\hline 115.2 & 28.4 \\
\hline 109.8 & 40.0 \\
\hline 101.3 & 41.5 \\
\hline
\end{tabular}

The variation of the total heat power input with traverse speed is shown in Figure 12. A good comparison can be observed between the Schmidt model and the CFD results in terms of total heat generation (power). As the traverse speed is increased, the total heat input from the tool increases. 


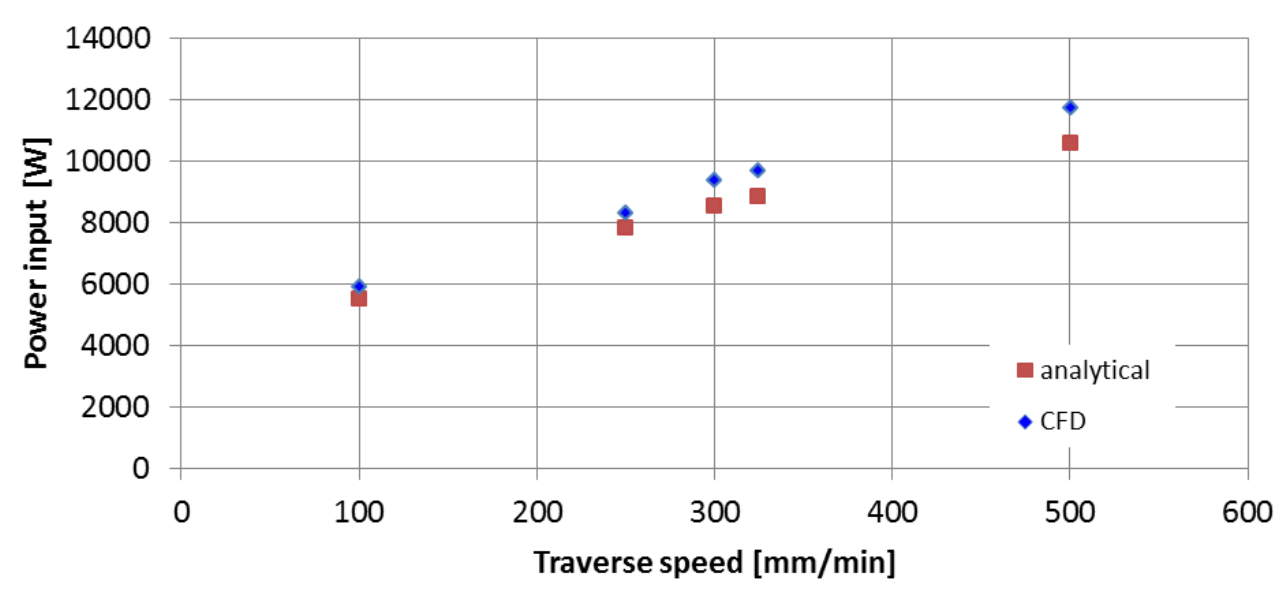

Figure 12 - Total power input during friction stir welding against traverse speed. Results from the analytical model from Schmidt $e t$ al. [11] and CFD are compared.

The same comparisons are performed for the volumetric heat generation from the pin. The power input from the tool pin is first established form the CFD simulations using equation (16) and the result divided by the pin volume. From, Schmidt et al. [11], the power input from the pin is given by:

$$
Q_{p, \text { sticking }}=\pi \tau \Omega R_{p}^{2}\left(2 H_{p}+\frac{2}{3} R_{p}\right)
$$

The results for the pin volumetric heat generation also agree satisfactory with each other and are shown in Figure 13.

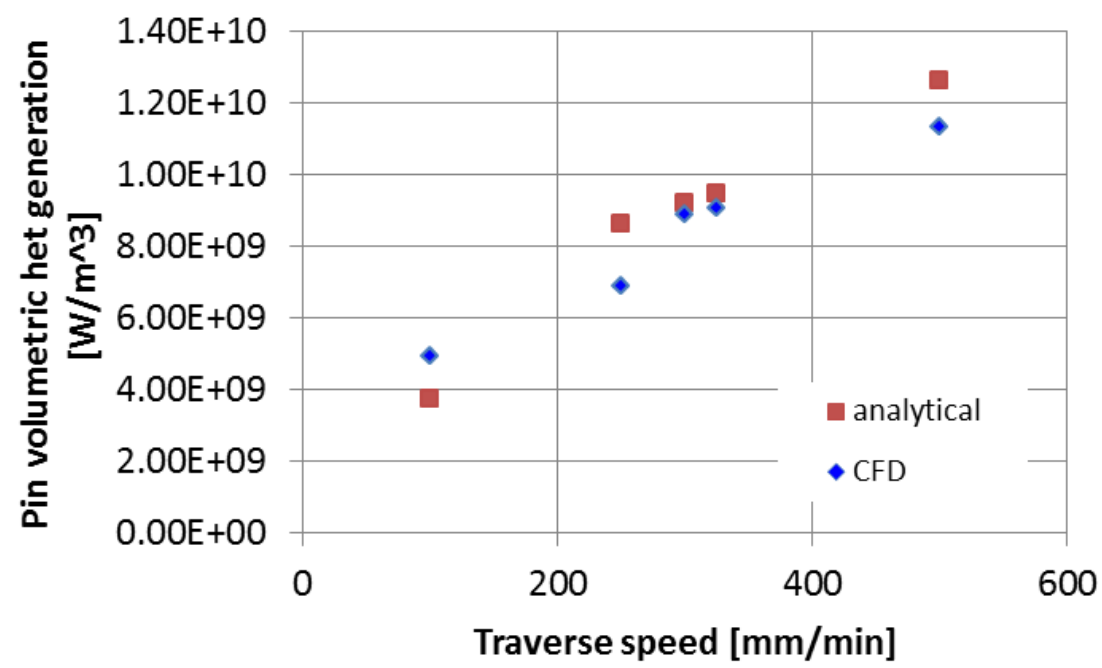

Figure 13 - Pin volumetric heat generation against traverse speed. Comparison of results from the analytical model by Schmidt et al. [11] and CFD.

Both of these comparisons confirm the validity of the model by Schmidt et al. [8] in the prediction of the overall power input. Nonetheless the Schmidt model still requires an empirical determination of the contact shear stress and this study discusses how the contact 
shear stress $\tau$ as a function of the tool speed can be used as an input to such an analytical model. The shear stresses developed at the tool surface is presented in Figure 14. In all cases, the maximum shear stress is at the front of the tool where the material has the minimum temperature (Figure 10) and hence a large viscosity while the minimum shear stress occurs at the rear of the tool where the temperature is higher and hence a lower viscosity.

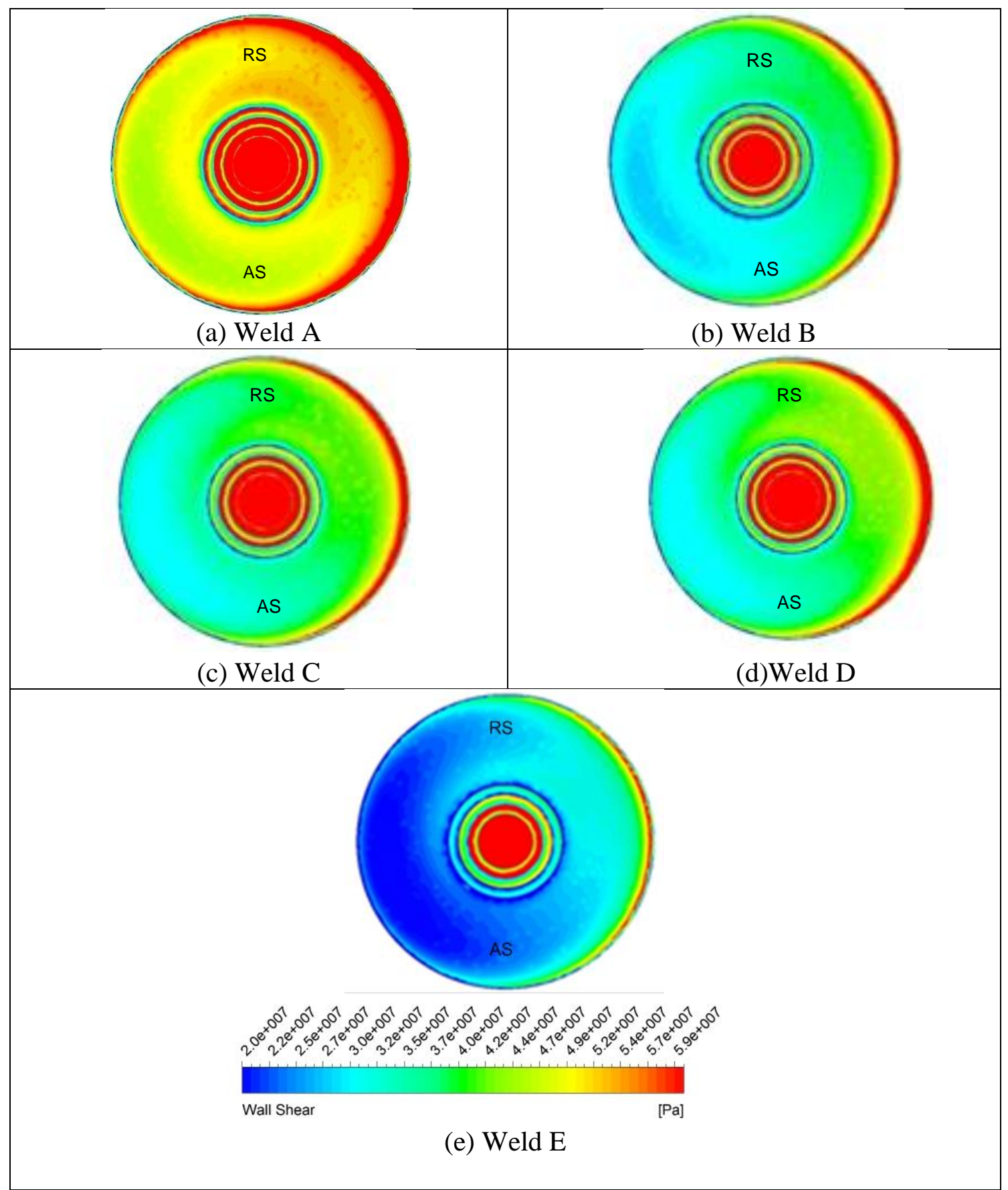

Figure 14 - Variation of the shear stress along the surface of the tool.

\subsection{Power distribution}

The power generation at the tool interface clearly has an important role in the understanding of how heat is being generated on the tool shoulder surface. As mentioned earlier, a linear equation (equation (1)) for the heat flux is usually used in the application to global models to predict residual distortions. The asymmetry of the heat generation is not considered in such a 
model. The results presented in this work clearly show that the asymmetry can be quite relevant especially for higher speed welds. It is therefore worth looking in more detail on how heat flux is distributed along the tool surface. Figure 15 shows the variation of surface heat flux with tool shoulder radius for the rear, front, retreating and advancing side of the tool for the different weld specimens. A comparison between analytical and actual predicted CFD heat flux (CFD full model) for weld $\mathrm{E}$ is given in Figure 16. A linear model following equation (1) is superimposed on this figure with the total shoulder heat flux defined and calculated through CFD simulations (Linear Khandakar - CFD heat input). The figure also presents the corresponding heat flux as would be obtained from equation (17) using the model by Schmidt et al. [11] and the corresponding prescribed contact shear as predicted from the CFD model (Linear Schmidt - CFD shear input).

In line with the observations on the stir zone, the heat flux reveals a substantial asymmetry on the rear, front, advancing and retreating sides particularly for the intermediate to high speed welds. In regions of higher temperature, the viscosity of the fluid will be lower and hence the shear stresses will be lower resulting in a lower heat flux generation. This can be clearly observed in the differences between the advancing and retreating sides. The advancing side displays a higher temperature signifying a lower viscosity and hence lower heat flux as compared to the retreating side. A single exception to this seems to be weld E produced with welding parameters of $700 \mathrm{RPM}$ and $500 \mathrm{~mm} / \mathrm{min}$. In this case, the difference in heat flux input between the advancing and retreating sides is minor even though the temperature field asymmetry is high. The velocity gradients in this case are playing a fundamental role in this balance of heat flux on both sides since the shear stress is also related to the magnitude of these velocity gradients. The rear side of the tool also has a lower heat flux input due to the higher temperature of the material being displaced towards the rear end of the tool. This occurs in all welds examined.

Another observation is the variation of the heat flux with radius. In the mid-radius region, the heat flux follows a rather linear variation. On the inner and outer parts of the tool radius, a non-linear variation is clearly observed with a higher heat flux towards the outer edge and a lower heat flux towards the pin when compared to the classical linear heat flux model. Since there is close agreement between the total heat input from the CFD model and the Schmidt model with the contact shear stress supplied from the CFD model, the linear models agree quite well with each other. Further work on the inclusion of a friction model requires tuning of the fundamental parameters which determine the sliding friction. 


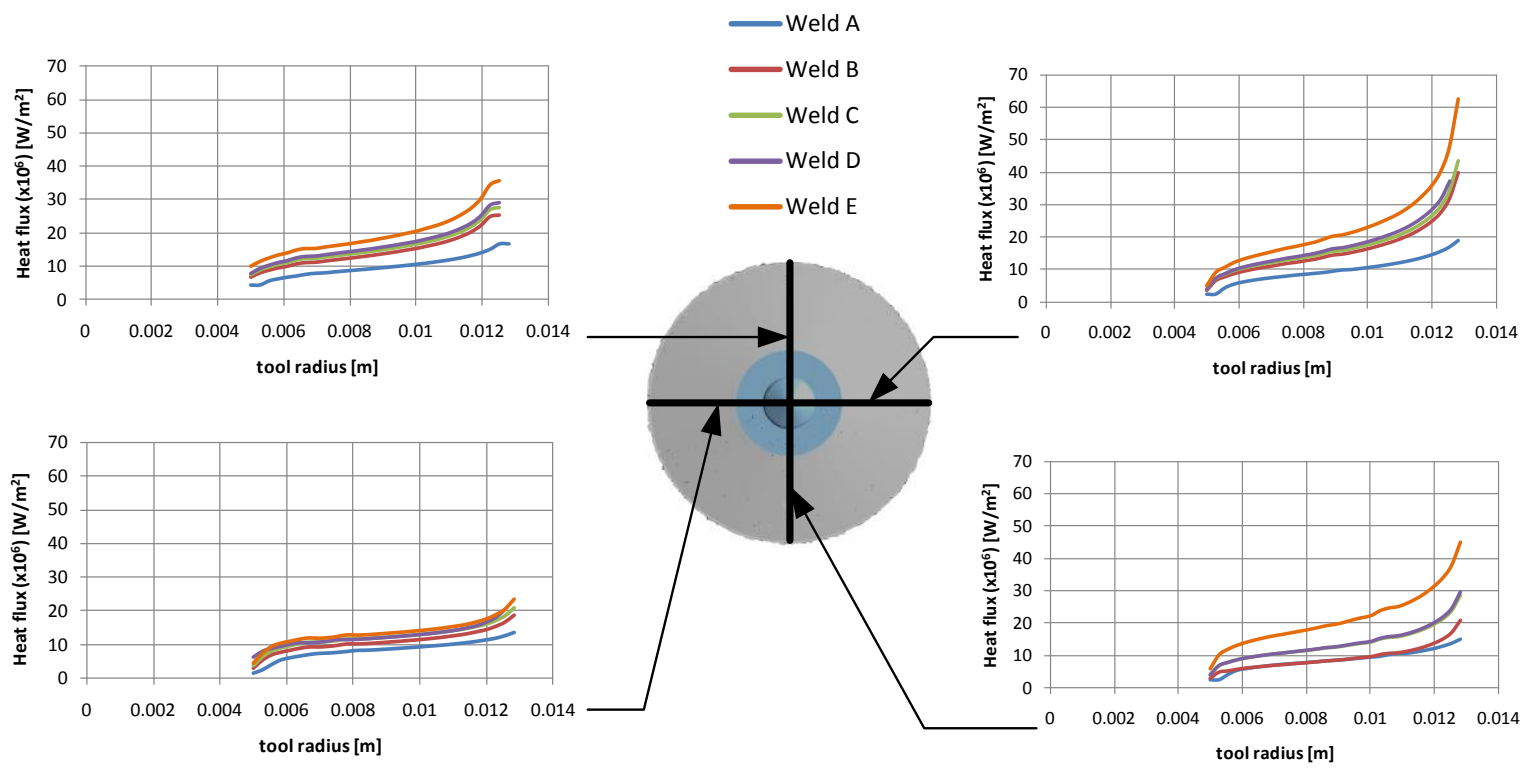

Figure 15 - Heat flux variation with radius around the tool surface for different welding parameters.
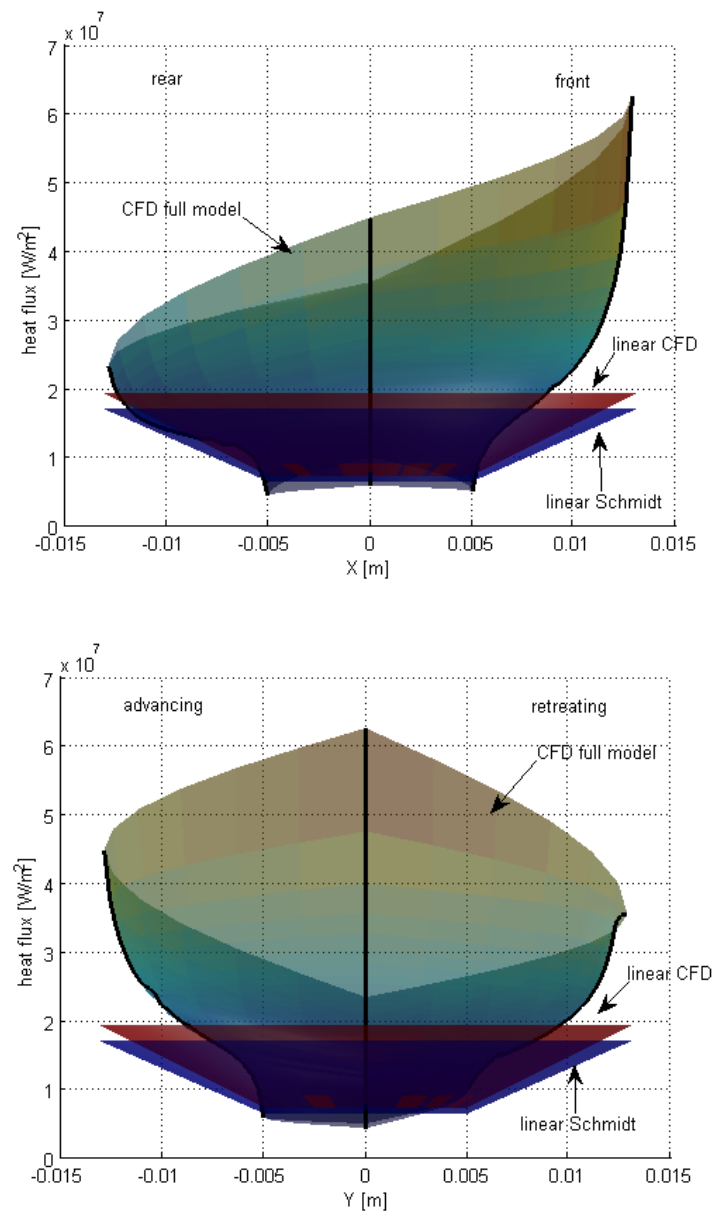


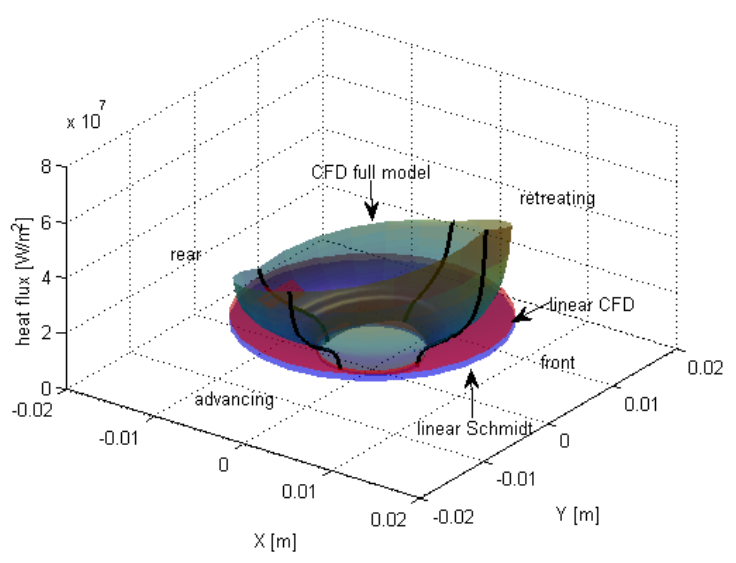

Figure 16 - Comparison of the heat flux for weld $E$ (fastest weld) from the CFD simulation (CFD full model) and the linear models, linear Khandakar - CFD heat input and linear Schmidt - CFD shear input

\section{Conclusions}

Identifying the shape of the stir zone is important in global model predictions. In particular, such regions undergo phase transformations that are also dependant on the accurate modelling of the thermal gradients and cooling rates. The use of local CFD models are thus an essential requirement for the accurate prediction of the thermo-elasto-plastic response of friction stir welded assemblies. Based on the velocity iso-surface (Figure 11) the temperature gradient along the thickness is quite significant for higher welding speed. This may have important consequences on the through thickness residual stresses possibly giving rise to more angular plate distortion.

The heat power input is found to be the controlling factor in the determination of the nugget shape which is in itself related to the welding speed. The power input as a function of the traverse speed was established in this work. This was also compared with an analytical model using the average contact shear stress calculated from the CFD approach. The findings further support the usefulness of these analytical models but such analytical approaches are heavily reliant on the accurate determination of the contact shear stress that is somewhat arbitrarily chosen unless backed up by local CFD models.

The weld speed has also been shown to affect the heat flux at the tool shoulder. The classical linear relationship between heat flux and tool radius was scrutinized and the results from the CFD model were compared with the heat flux from a linear model. A considerable deviation from linearity was observed at the tool shoulder inner and outer regions. In addition, an asymmetrical variation around the tool shoulder is observed. Higher temperatures were computed on the advancing side of the tool compared to the retreating side. Albeit, a high temperature zone does not directly mean a high power input from the shoulder, but is more a function of the temperature and the visco-plastic material response - at higher temperatures. At higher temperatures for example, the viscosity decreases and hence the shear stress and power decreases. An interesting case was the high rotational speed case where the heat flux input from the advancing side was found to be similar to the retreating side. In this weld, the influence of higher strain rates comes into play which also affects the viscosity. These findings are interlinked with how the stir zone geometry develops. 
In summary, the following conclusions may be drawn giving further insight on the appropriate selection of FSW parameters with respect to minimization of residual stresses and distortions in $6 \mathrm{~mm}$ thick friction stir welded DH36 steel plate:

- The transverse heat input ratio (THIR) is one of the crucial determining factors of the stir zone shape and size

- Higher THIR ratios (low traverse speed compared to the rotational speed) leads to a more uniform heated zone along the plate thickness.

- Lower THIR ratios (high transverse speed compared to the rotational speed) leads to high temperature gradients through the thickness.

The physics of the heat power input process were established for the different welding speeds in order to be of use in global model prediction of residual distortions:

- The heat input was found to increase with an increase in traverse speed.

- The contact shear stress from the simulations was used in an analytical model by Schmidt et al. and results for the power compared with the CFD results. The outcome confirmed that such analytical tools may be integrated with a CFD approach which can establish the contact shear stress.

- For DH36 steel, the heat flux at the shoulder interface was found to be highly nonlinear particularly in the inner and outermost shoulder radii. An asymmetry in the rotational direction of the heat flux at the tool shoulder was also observed with the rear of the tool showing lesser heat generation compared to the front. This is attributed to the higher temperature generation on the rear resulting in a lower viscosity and hence lower shear stress

- The advancing side results in a lower heat flux input than the retreating side, contrary to what is seen in the temperature profiles. This can also be attributed to the lower viscosity and lower shear stress. An exception to this was found with the high rotational speed case where although the temperature asymmetry is high, the heat flux asymmetry between the advancing and retreating side is reduced.

- This last point highlights the complexity of the heat and mass transfer phenomenon as material is transported from the front to the rear of the tool.

\section{Acknowledgements}

This study is being funded by the European Commission in call FP7-SST-2012-RTD-1 under the project titled High Integrity Low Distortion Assembly - HILDA.

\section{References}

[1] Mishra R.S. and Ma Z.Y., 'Friction Stir Welding and Processing,' Materials Science and Engineering R 50 (2005), 1-78.

[2] Mishra R.S., De P.S. and Kumar, N., 'Friction Stir Welding and Processing,' ISBN 9783-319-07042-1, Springer

[3] He X., Gu F., and Ball A.,'A Review of Numerical Analysis of Friction Stir Welding,' Progress in Materials Science, 65, 2014, 1-66 
[4] Riahi M, Nazari H, 'Analysis of transient temperature and residual thermal stresses in friction stir welding of aluminum alloy 6061-T6 via numerical simulation,' International Journal of Advanced Manufacturing Technology, 55(1):143-152. DOI: 10.1007/s00170-0103038-z.

[5] Yan DY, Wu AP, Silvanus J, et al. 'Predicting residual distortion of aluminum alloy stiffened sheet after friction stir welding by numerical simulation'. Mater Des 2011; 32: 2284-2291.

[6] Camilleri D, Micallef D and Mollicone P, 'Thermal Stresses and Distortion Developed in Mild Steel DH36 Friction Stir Welded Plates: An Experimental and Numerical Assessment,' Journal of Thermal Stresses (in print)

[7] Micallef D, Camilleri D and Mollicone P, 2013, 'Simplified Thermo-elastoplastic Numerical Modelling Techniques Applied to Friction Stir Welding of Mild Steel,' ASME 2013 Int. Mech. Eng. Congress \& Exposition, San Diego, USA.

[8] Zhu X.K., and Chao Y.J., ' Numerical Simulation of Transient Temperature and Residual Stresses in Friction Stir Welding of 304L Stainless Steel,' Journal of Materials Processing Technology, Vol. 146, 2004, pp 263-272.

[9] Khandkar MZH, Khan JA, Reynolds AP. A Thermal Model of the Friction Stir Welding Process', Proceedings of IMECE2002, ASME International Mechanical Engineering Congress \& Exposition, New Orleans, Louisiana, November, 2002.

[10] Riahi H., and Nazari H., 'Analysis of Transient Temperature and Residual Thermal Stresses in Friction Stir Welding of Aluminium Alloy 6061-t6 via Numerical Simulation,' Int. Journal of Materials Processing Technology, vol. 146, no.2, 2011, pp 143-152.

[11] Schmidt H., Hattel J. and Wert J., 'An Analytical Model for the Heat Generation in Friction Stir Welding,' Modelling and Simulation in Materials Science and Engineering, 2004, vol 12, pp143-157

[12] Qin X., 'Thermo-elasto-visco-plastic Modelling of Friction Stir Welding in an Eulerian Reference Frame,' UMI Dissertation Publishing, ProQuest LLC, UMI No. 3374535, USA.

[13] Nandan R., Roy G.G. and Debroy T., 'Numerical Simulation of Three Dimensional Heat Transfer and Plastic Flow during Friction Stir Welding,' Metallurgical and Materials Transactions A, Vol 37A, 2006. 1247-1259.

[14] Camilleri D., Mollicone P. and Gray T.G.F., 'Computational Methods and Experimental Validation of Welding Distortion Models,' Journal of Materials Design and Application, Vol. 221, no. 4, 2007, pp. 235-249.

[15] Gao-qiang C., Qing-yu S., Yu-jia L., Yan-jun S., Qi-lei D., Jin-yao J., Yu-can Z. and Jian-jun W., 'Computational Fluid Dynamics Studies on Heat Generation during Friction Stir Welding of Aluminium Alloy,' Computational Materials Science, Vol 79, 2013, pp540-546. 
[16] Padmanaban R., Ratna Kishore V. and Balusamy V., 'Numerical Simulation of Temperature Distribution and Material Flow During Friction Stir Welding of Dissimilar Aluminum Alloys,' Procedia Engineering, Vol. 97, 2014, 854-863

[17] Su H., Wu C.S., Pittner A. and Rethmeier M., 'Thermal Energy Generation and Distribution in Friction Stir Welding of Aluminum Alloys,' Energy, Vol.77, 2014, 720-731

[18] Nandan R., Roy G.G., Lienert J. and DebRoy T., ' Numerical Modelling of 3D Plastic Flow and Heat Transfer during Friction Stir Welding of Stainless Steel,' Science and Technology of Welding and Joining, Vol. 11(5), 2006, pp.526-537.

[19] Gray T., Camilleri D., and McPherson N., 'Control of Welding Distortion in Thin Plate Fabrication: Design support exploiting computational simulation,' ISBN: 978-0-85709-047-8 Woodhead Publishing Ltd, 2014, Cambridge U.K.

[20] Toumpis A., Galloway A., Cater S., Micallef D., Camilleri D., Poletz N., and Arbaoui L., 'Advances in Friction Stir Welding of Steel - Project HILDA,' Proc. of Int. Conf. on Transport Research Arena, 2014, Paris, France.

[21] Chuimenti M., Cervera M., Agelet de Saracibar C. and Dialami N., 'Numerical Modeling of Friction Stir Welding Processes,' Computer Methods in Applied Mechanics and Engineering, Vol 254, 2013, pp 353-369.

[22] Toumpis A., Galloway A., Cater S., and McPherson N., 2014 Development of a Process Envelope for Friction Stir Welding of DH36 Steel - A Step Change, Materials \& Design, 62, 64-75

[23] Wang H., Colegrove P.A. and dos Santos J.F., ' Hybrid Modelling of 7449-T7 Aluminium Alloy Friction Stir Welded Joints,' Science and Technology of Welding and Joining Vol. 18 no. 2, (2013) pp. 147-153. 